\title{
The elevated expression of TLR4 and MMP9 in human abdominal aortic aneurysm tissues and its implication
}

\author{
Tan $\mathrm{Li}^{1}$, Xintong $\mathrm{Li}^{2}$, Xiaozheng Liu' ${ }^{1}$, Jun Yang ${ }^{1 *}$ (D) and Chunyan $\mathrm{Ma}^{1 *}$
}

\begin{abstract}
Background: Toll-like receptor 4 (TLR4) and matrix metalloproteinase 9 (MMP9) have been investigated to play significant roles in the formation of abdominal aortic aneurysm (AAA). But the reports on the expression pattern of TLR4 and MMP9 in human AAA specimens were relatively scant. The aim of this study was to make a detailed analysis of TLR4 and MMP9 expression in situ and their association with clinical parameters involved in human AAA.
\end{abstract}

Methods: 40 AAA specimens were obtained from full-thickness aneurysmal tissues at the maximal dilation area during the open surgical repair, and 8 non-aneurysmal abdominal aortas from transplant donors served as controls. Expression of TLR4 and MMP9 protein was determined by immunohistochemistry.

Results: There were increased levels of TLR4 and MMP9 expression in human AAA tissues. Compared with macrophages or SMCs, lymphocytes showed a higher positive rate of TLR4 and MMP9 staining, and an elevated ratio of high MMP9 expression (all $P<0.05$ ). There existed a significant association between TLR4 and MMP9 expression $(r=0.767, P<0.001)$, and both TLR4 and MMP9 levels were statistically related to circulating CRP. Moreover, TLR4 expression in situ indicated a positive correlation with its serum level $(r=0.654, P=0.006)$. Multiple analysis revealed that high TLR4 expression in situ was associated with the risk of large AAA $(O R=6.211,95 \% \mathrm{Cl}=1.226-31.480$, $P=0.027)$, while high MMP9 expression was correlated to the presence of thrombus within AAA (OR $=5.494$, $95 \% \mathrm{Cl}=1.181-25.562, P=0.030$ ), separately compared with their low expression.

Conclusions: This study confirmed the overexpression of TLR4 and MMP9 in human AAA tissues, and their close relationship implying in the pathogenesis of AAA. We further provided evidence that TLR4 had a potential effect on AAA size and MMP9 could influence the occurrence of thrombus within AAA.

Keywords: Abdominal aortic aneurysm, Toll-like receptor 4, Matrix metalloproteinase 9, Expression, Immunohistochemistry

\section{Background}

Abdominal aortic aneurysm (AAA) is a progressive focal dilatation and weakening of the abdominal aorta, which may be accompanied by an intraluminal thrombus [1].

\footnotetext{
*Correspondence: yangjun@cmu1h.com; cmu1h_mcy@126.com ${ }^{1}$ Department of Cardiovascular Ultrasound, the First Hospital of China Medical University, No. 155 Nanjing Bei Street, Heping District, Shenyang 110001, Liaoning Province, People's Republic of China Full list of author information is available at the end of the article
}

The formation of AAA is a multifactorial process, the triggers of which are not fully understood [2]. However, inflammation and extracellular matrix (ECM) degeneration in aortic wall that result in medial layer destruction and aortic diameter enlargement are the common pathological features of AAA [3].

As one of the most well-characterized inflammationrelated molecules, toll-like receptor 4 (TLR4) plays a critical role in mediating vascular inflammation and 
remodeling [4-6]. Immune inflammatory cells are primary sources of TLR4. In addition, TLR4 can also be produced by vascular-related cells, such as smooth muscle cells (SMCs) $[7,8]$. Some cell and animal experiments reported that TLR4 contributed to AAA formation mainly by promoting the infiltration of inflammatory cells, maintaining inflammatory status of vascular SMCs, and inducing cross-talk with other pathways [9, 10]. However, the expression of TLR4 in human AAA tissues has been rarely investigated. Matrix metalloproteinase 9 (MMP9) is an important proteolytic enzyme and has been well known to involve in the pathogenesis of AAA with the action of degrading multiple extracellular components in aortic wall $[11,12]$. MMP9 can be expressed by SMCs and infiltrating inflammatory cells, such as lymphocytes and macrophages [13]. There were consistent data that MMP9 expression was increased in the aortic wall of AAA $[14,15]$, but the relationship between MMP9 expression level and AAA size was controversial [16-18]. Recently, some experiments demonstrated that the activation of TLR4 could induce MMP9 production in SMCs and macrophages [19-21], on the contrary, lack of TLR4 function attenuated MMP9 expression [22]. During the process of aortic tissue damage and remodeling, released fragments from ECM degradation can also trigger TLR4 expression and its signaling activation [9]. Above evidence suggested that TLR4 pathway linked to MMP9 appeared to have a key effect on AAA formation [23], but the combined analysis of TLR4 and MMP9 expression in AAA tissues was lacking.

In previous studies, we have preliminarily demonstrated the elevated serum levels of TLR4 and MMP9 being closely related to the existence of AAA [24, 25]. The present study aimed to further analyze the expression characteristics and correlation of TLR4 and MMP9 in human AAA tissues by means of immunohistochemistry, and examine the association of TLR4 and MMP9 protein expression in situ with clinical parameters relevant to AAA. Our research would offer additional insight into the importance of TLR4 and MMP9 in the underlying pathogenesis of AAA.

\section{Methods}

\section{Study population}

Wall specimens of 40 AAA patients were obtained from full-thickness aneurysmal infrarenal abdominal aortic tissues at the area of maximal dilation during the open surgical repair in our hospital. Control samples of 8 nonaneurysmal infrarenal abdominal aortas were obtained from human organ donors during kidney transplantation. Specimens were immediately fixed in $10 \%$ formalin and after $24 \mathrm{~h}$ embedded in paraffin. Clinical data collection relied on patients' medical records. The imaging characteristics of AAA patients were assessed by computed tomography angiography (CTA). The subjects with severe vascular stenosis, autoimmune diseases, infectious diseases, malignant tumors, hematological system diseases, coronary heart diseases, congenital heart diseases, severe organ failure or previous aortic surgery were excluded. The study was approved by the Ethics Committee of the First Hospital of China Medical University (Shenyang, China) and was according to the Declaration of Helsinki. Written informed consent was obtained from each subject.

\section{Protein expression in situ by immunohistochemistry}

According to the manufacturer's instructions, we performed the immunohistochemical staining procedure on the sections of paraffin-embedded aortic tissue $(4 \mu \mathrm{m})$. In brief, slides were antigen retrieved with boiling citric acid buffer ( $\mathrm{pH} 6.0$ ), endogenous peroxidase activity was blocked with $3 \%$ hydrogen peroxide solution for $10 \mathrm{~min}$, and the sections were washed with phosphate-buffered saline ( $\mathrm{pH}$ 7.4). To avoid nonspecific binding, $10 \%$ normal goat serum was used to block tissue collagen for $10 \mathrm{~min}$. Then, the sections were incubated with polyclonal antibodies for TLR4 (YM3387, 1:300, ImmunoWay, USA) and MMP9 (YT5357, 1:200, ImmunoWay, USA) at $37{ }^{\circ} \mathrm{C}$ for $1 \mathrm{~h}$. For cell characterization, AAA samples were also treated with ready-to-use antibodies against lymphocytes (anti-CD3, Kit-0004, Maixin Inc., China), macrophages (anti-CD68, Kit-0026, Maixin Inc., China) and vascular SMCs (anti-SMA, Kit-0006, Maixin Inc., China). Thereafter, the sections were incubated with biotinylated secondary goat anti-rabbit antibody (Kit-9710, Maixin Inc., China) for $10 \mathrm{~min}$, followed by streptavidin-biotin peroxidase for another $10 \mathrm{~min}$, and diaminobenzidine (DAB) was used as the chromogen. Finally, slides were dehydrated and sealed for microscopy observation.

TLR4 and MMP9 protein expression was scored using a semi-quantitative method that considered both the staining intensity and proportion [26, 27]. In order to avoid staining underestimation owing to the regional variations, 5 continuous $\times 200$ microscopy views of each stained specimen with the largest amount of positive stained cells were captured and recorded [27]. In accordance with the double-blind principle, two experienced investigators evaluated the staining results. Briefly, staining intensity was scored as 0 (no staining), 1 (mild staining), 2 (moderate staining) and 3 (strong staining), while staining proportion was scored as $0(\leq 5 \%$ positive stained), 1 ( $6-25 \%$ positive stained), 2 ( $26-50 \%$ positive stained), 3 (51-75\% positive stained) and 4 ( $\geq 76 \%$ positive stained). The final immunoreactivity score was obtained by multiplying the score of staining intensity and proportion, which was graded as negative $(-)$ of 0 
score, weak positive $(+)$ of $1-4$ score, moderate positive $(++)$ of 5-8 score and strong positive $(+++)$ of $9-12$ score.

\section{Serum levels of TLR4 and MMP9}

According to our previously published data [24, 25], a total of 16 AAA patients with the information of serum TLR4 $(8.09 \pm 4.31 \mathrm{ng} / \mathrm{mL})$ and MMP9 $(193.89 \pm 71.41 \mathrm{ng} /$ $\mathrm{mL}$ ) levels were involved in further correlation analysis of TLR4 and MMP9 expression in aortic tissue and serum of AAA patients.

\section{Statistical analysis}

All data were analyzed with SPSS 17.0 software. Continuous variables were reported as mean values and standard deviations, while categorical variables were represented as numbers and percentages. Values of variables were compared with Fisher's exact test, $\chi^{2}$ test, independentsample t-test or Mann-Whitney U-test as appropriate. We utilized Spearman's rank correlation analysis to determine the association between TLR4 and MMP9 expression, and the relationship of their levels in situ with common circulating biomarkers and maximal aortic size. Multiple logistic regression models were performed to examine the predictive value of high TLR4 and MMP9 expression in the risk of large AAA $(>5.5 \mathrm{~cm})$ or thrombus within AAA after adjusting the possible confounding factors. A two-sided $P$ value $<0.05$ was considered statistically significant.

\section{Results}

\section{TLR4 and MMP9 expression in AAA and control tissues}

Negative immunostaining for TLR4 and MMP9 was observed in non-aneurysmal control aortas (Fig. 1). As shown in Figs. 2, 3 and 4, immunohistochemical analysis of human AAA tissue samples demonstrated the positive staining (brown) of TLR4 and MMP9 predominantly in lymphocytes, macrophages and SMCs, and inflammatory cell and SMC markers were also detected in the AAA wall. Table 1 presents data on the expression levels of TLR4 and MMP9 in overall cells, lymphocytes, macrophages and SMCs in AAA samples and control aortas. Our results showed that there were different levels of TLR4 and MMP9 expression in AAA tissues, which were significantly higher than those in controls (all $P<0.001$ ).

We further analyzed the positive staining and high expression of TLR4 and MMP9 between different cells in AAA specimens, as shown in Table 2. High expression incorporated moderate and strong positive staining, while low expression included negative and weak positive staining. Higher positive rate of TLR4 expression was found in lymphocytes compared with macrophages or SMCs (all $P<0.05$ ). The ratio of MMP9 positive staining and high expression in lymphocytes was statistically elevated compared to macrophages or SMCs, respectively, while MMP9 positivity in macrophages was observed lower than that in SMCs (all $P<0.05$ ). Additionally, compared with TLR4 expression, MMP9 had an increased ratio of high expression in lymphocytes $(P=0.016)$, whereas the pattern of TLR4 and MMP9 staining was not significantly different in overall cells, macrophages and SMCs (Table 2).

\section{Clinical characteristics of AAA patients based on different TLR4 and MMP9 expression}

Clinical characteristics of AAA patients based on different TLR4 and MMP9 expression in situ are shown in Table 3. The results indicated that high TLR4 expression was more frequent in smoking patients and large AAA compared to low TLR4 expression $(P=0.015$ and 0.022 ,
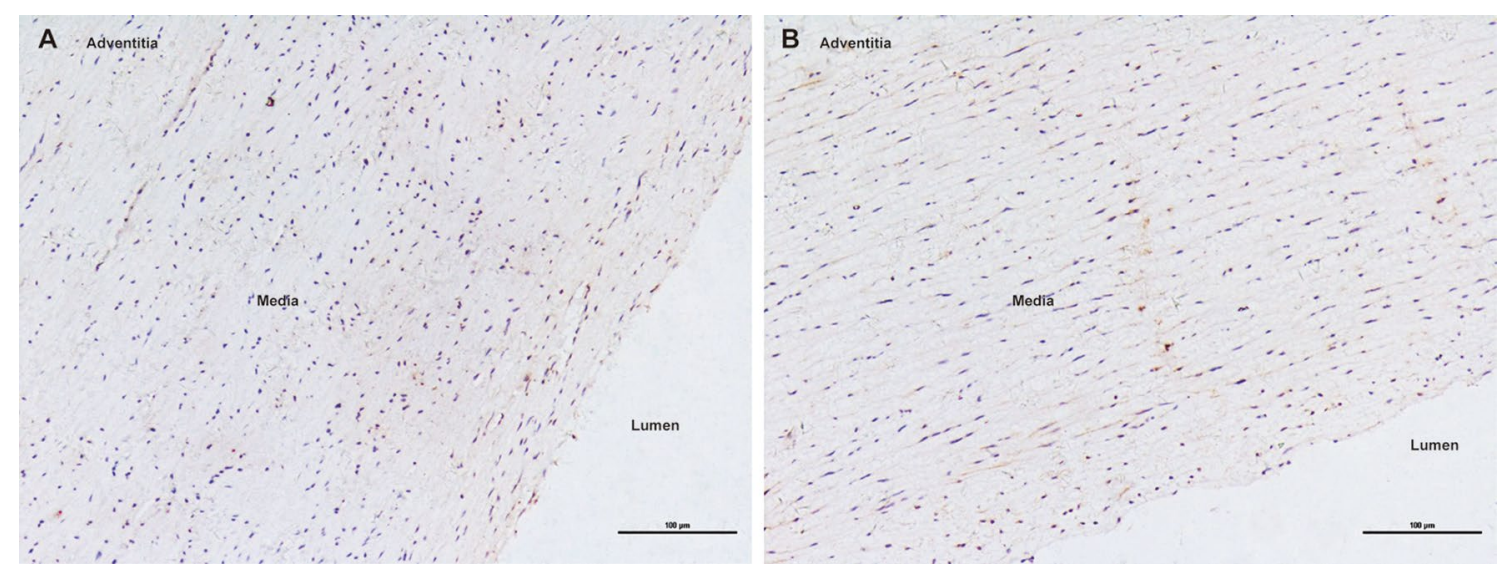

Fig. 1 Negative expression of TLR4 (a) and MMP9 (b) in control aortas under 200x magnification (Scale bars =100 $\mu \mathrm{m}$ ) 

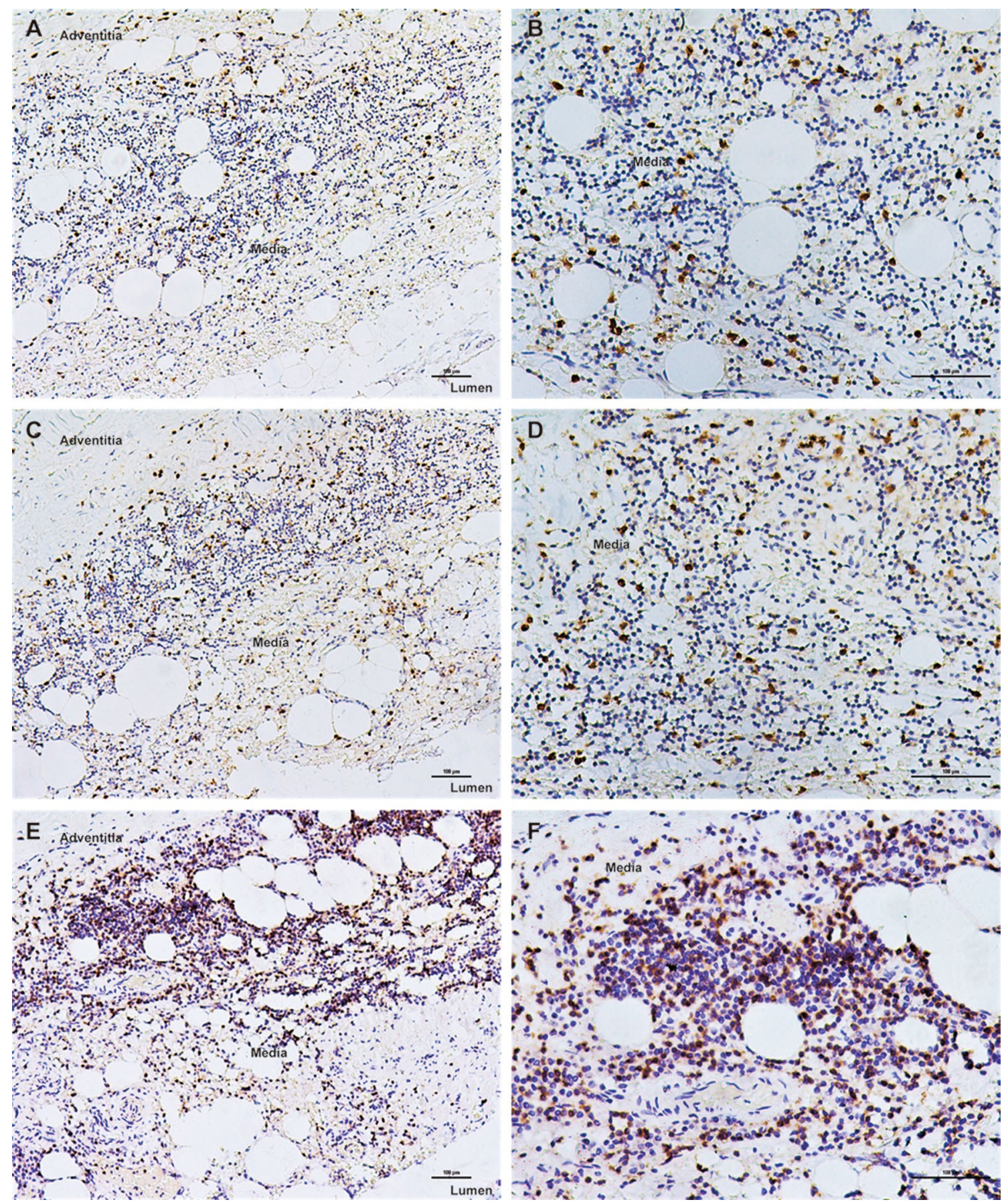

Fig. 2 Immunohistochemical staining of TLR4, MMP9 and CD3 in lymphocytes within human AAA tissue samples (Scale bars=100 $\mu$ m). a TLR4 under 100x magnification; b TLR4 under 200x magnification; c MMP9 under 100x magnification; d MMP9 under 200x magnification; e lymphocyte marker CD3 under 100x magnification; f lymphocyte marker CD3 under 200x magnification

respectively), while high MMP9 expression had a significantly higher ratio of smokers and thrombus within AAA than low MMP9 expression $(P=0.025$ and 0.013 , respectively).

\section{Correlation analysis}

Correlation analysis revealed that either TLR4 or MMP9 expression level in AAA tissues was statistically associated with circulating $C$-reactive protein $(\mathrm{CRP})(\mathrm{r}=0.419$ and 0.352 , respectively; all $P<0.05)$, and a significant 

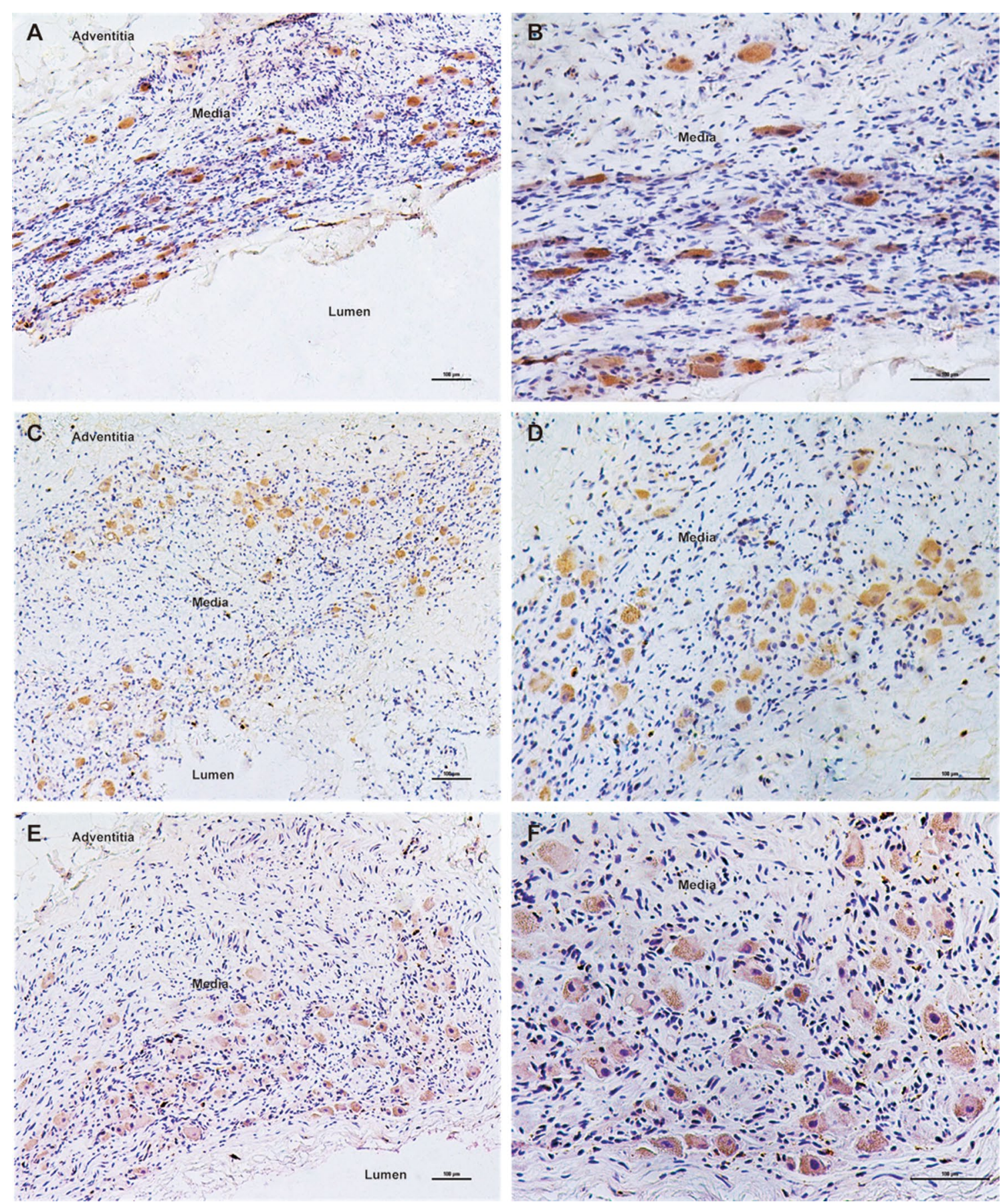

Fig. 3 Immunohistochemical staining of TLR4, MMP9 and CD68 in macrophages within human AAA tissue samples (Scale bars $=100 \mu m$ ). a TLR4 under 100× magnification; b TLR4 under 200× magnification; c MMP9 under 100× magnification; d MMP9 under 200× magnification; e macrophage marker CD68 under 100× magnification; f macrophage marker CD68 under 200× magnification

correlation was also observed between TLR4 and MMP9 expression level $(\mathrm{r}=0.767, P<0.001)$ (Table 4$)$. Moreover, TLR4 expression in situ indicated a positive association with its serum level $(r=0.654, P=0.006)$ (Fig. 5), however, there was no significant relationship between aortic
MMP9 expression and serum MMP9 level $(\mathrm{r}=0.396$, $P=0.129)$.

Based on univariate analysis, smoking and hypertension were selected as potential confounding factors $(P<0.100)$, which were adjusted in the regression 

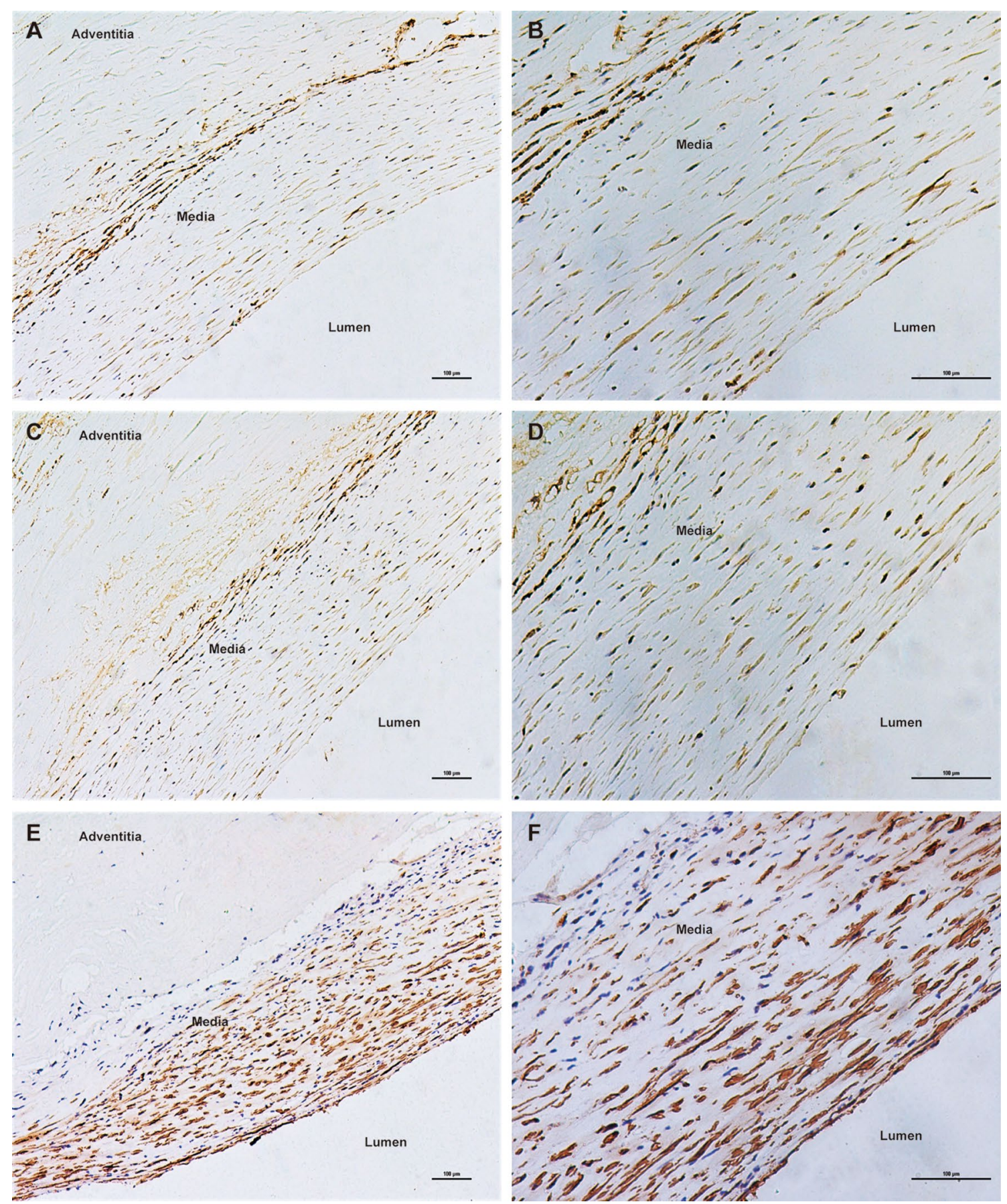

Fig. 4 Immunohistochemical staining of TLR4, MMP9 and SMA in SMCs within human AAA tissue samples (Scale bars = $100 \mu \mathrm{m}$ ). a TLR4 under 100x magnification; b TLR4 under 200x magnification; c MMP9 under 100x magnification; d MMP9 under 200x magnification; e SMC marker SMA under $100 \times$ magnification; f SMC marker SMA under 200× magnification

model as appropriate. After adjusting hypertension, high TLR4 expression in situ was independently associated with an increased risk of large AAA $(\mathrm{OR}=6.211$, $95 \% \mathrm{CI}=1.226-31.480, P=0.027)$, while high MMP9 expression was significantly related to the presence of thrombus within AAA after the adjustment for smoking and hypertension $(\mathrm{OR}=5.494,95 \% \mathrm{CI}=1.181$ 25.562, $P=0.030$ ) (Table 5). 
Table 1 TLR4 and MMP9 expression in situ between AAA patients and controls

\begin{tabular}{|c|c|c|c|c|c|c|c|c|c|c|c|c|}
\hline & & \multirow[t]{2}{*}{$\mathbf{n}$} & \multicolumn{5}{|c|}{ TLR4 expression level } & \multicolumn{5}{|c|}{ MMP9 expression level } \\
\hline & & & $(+++)$ & $(++)$ & $(+)$ & $(-)$ & $P$ value & $(+++)$ & $(++)$ & $(+)$ & $(-)$ & $P$ value \\
\hline \multirow[t]{2}{*}{ Overall, n } & AAA & 40 & 6 & 7 & 18 & 9 & $<0.001$ & 6 & 15 & 12 & 7 & $<0.001$ \\
\hline & CON & 8 & 0 & 0 & 0 & 8 & & 0 & 0 & 0 & 8 & \\
\hline \multirow[t]{2}{*}{ Lymphocytes, n } & AAA & 40 & 2 & 8 & 17 & 13 & $<0.001$ & 3 & 17 & 12 & 8 & $<0.001$ \\
\hline & $\mathrm{CON}$ & 8 & 0 & 0 & 0 & 8 & & 0 & 0 & 0 & 8 & \\
\hline \multirow[t]{2}{*}{ Macrophages, n } & AAA & 40 & 1 & 2 & 2 & 35 & $<0.001$ & 2 & 0 & 1 & 37 & $<0.001$ \\
\hline & $\mathrm{CON}$ & 8 & 0 & 0 & 0 & 8 & & 0 & 0 & 0 & 8 & \\
\hline \multirow[t]{2}{*}{ SMCs, n } & AAA & 40 & 3 & 3 & 7 & 27 & $<0.001$ & 2 & 4 & 5 & 29 & $<0.001$ \\
\hline & CON & 8 & 0 & 0 & 0 & 8 & & 0 & 0 & 0 & 8 & \\
\hline
\end{tabular}

Table 2 TLR4 and MMP9 expression in situ between different cells in AAA patients

\begin{tabular}{lll}
\hline Protein expression & TLR4 $(\mathbf{n}=\mathbf{4 0})$ & MMP9 $(\mathbf{n}=\mathbf{4 0})$ \\
\hline $\begin{array}{l}\text { Overall } \\
\text { Positive, } \mathrm{n}(\%)\end{array}$ & $31(77.5 \%)$ & $33(89.2 \%)$ \\
High, $\mathrm{n}(\%)$ & $13(32.5 \%)$ & $21(52.5 \%)$ \\
$\begin{array}{l}\text { Lymphocytes } \\
\text { Positive, } \mathrm{n}(\%)\end{array}$ & $27(67.5 \%)^{* \#}$ & $32(80.0 \%)^{* \#}$ \\
High, $\mathrm{n}(\%)$ & $10(25.0 \%)^{*}$ & $20(50.0 \%)^{* \#}$ \\
Macrophages & & \\
Positive, $\mathrm{n}(\%)$ & $5(12.5 \%)$ & $3(7.5 \%)^{\&}$ \\
High, $\mathrm{n}(\%)$ & $3(7.5 \%)$ & $2(5.0 \%)$ \\
SMCs & & $11(27.5 \%)$ \\
Positive, $\mathrm{n}(\%)$ & $13(32.5 \%)$ & $6(15.0 \%)$ \\
High, $\mathrm{n}(\%)$ & $6(15.0 \%)$ &
\end{tabular}

${ }^{*} P<0.05$ : Lymphocytes vs. Macrophages, ${ }^{\#} P<0.05$ : Lymphocytes vs. SMCs, ${ }^{\circledR} P<0.05$ : Macrophages vs. SMCs, ${ }^{*} P<0.05$ : TLR4 vs. MMP9

\section{Discussion}

Current evidence indicates that AAA is characterized by the inflammation and proteolytic degradation of aortic wall, which play a fundamental role in the evolution of disease [28]. Recently, a special focus has been devoted to TLR4 and MMP9. To our knowledge, this was the first study concerning the combined analysis of MMP9 and TLR4 expression in human AAA tissues. We revealed a significantly upregulated expression of TLR4 and MMP9 in AAA samples. However, there was no obvious TLR4 and MMP9 immunostaining in non-aneurysmal aortas, indicating the basal level undetectable. Furthermore, both TLR4 and MMP9 were mainly localized in inflammatory infiltrates and SMCs.

As is known, marked accumulation of infiltrating inflammatory cells, such as lymphocytes and macrophages, is the histological hallmark of AAA wall $[23,29,30]$. Similarly, we found that the most abundant inflammatory cells detected inside AAA wall were lymphocytes and macrophages. Although the pathogenesis of AAA remains largely obscure, expression of many genes implicated in inflammation and matrix degradation has been described as elevated in biopsies of human AAA [30]. TLR4 is a useful marker for assessing inflammatory status and vascular damage, and its activation has been reported to play a crucial role in aortic remodeling and AAA formation [4-6, 21]. On reviewing the literature, we found that concerns regarding TLR4 expression in AAA tissues were not taken seriously enough. Jabłońska et al. revealed the higher expression of TLR4 by qRT-PCR in the blood compared with the aortic wall tissue of AAA patients [31]. Utilizing immunostaining, only two studies to date reported the expression level of TLR4 in AAA lesions and were based on small sample size of less than ten. Lai et al. found that human AAA exhibited high TLR4 expression that was only localized to SMCs [10], while the presence of high levels of TLR4 in association with lymphocytes and macrophages was demonstrated by Vorkapic et al. [9]. Because of its capacity to degrade multiple components of ECM, MMP9 has been shown to participate in an important mechanism in the formation and expansion of AAA [11, 12, 32]. There were supporting data that the content of MMP9 was significantly increased in the aortic wall of AAA and MMP9 staining was positive for inflammatory cells and vascular-related cells $[15,33,34]$.

In the current study, we analyzed 40 AAA tissue samples and observed that lymphocytes, subsequently SMCs and macrophages were the main source of TLR4 and MMP9 in AAA. Compared with SMCs or macrophages, lymphocytes showed a significantly higher ratio of positive TLR4 and MMP9 staining, and exhibited a larger proportion of high MMP9 expression. In addition, MMP9 positivity in SMCs was higher than that in macrophages. Taken together, these findings may emphasize the importance of these two genes attributing to AAA pathogenesis. Interestingly, except 
Table 3 Baseline characteristics of AAA patients based on different TLR4 and MMP9 expression in situ

\begin{tabular}{|c|c|c|c|c|c|c|}
\hline \multirow[t]{2}{*}{ Variables } & \multicolumn{3}{|l|}{ TLR4 } & \multicolumn{3}{|l|}{ MMP9 } \\
\hline & Low $(n=27)$ & $\operatorname{High}(n=13)$ & $P$ value & Low $(n=19)$ & High $(n=21)$ & $P$ value \\
\hline Age, years & $61.56 \pm 8.12$ & $59.00 \pm 7.87$ & 0.352 & $62.00 \pm 9.24$ & $59.57 \pm 6.77$ & 0.279 \\
\hline Male, n (\%) & $23(85.2 \%)$ & $10(76.9 \%)$ & 0.408 & $16(84.2 \%)$ & $17(81.0 \%)$ & 0.559 \\
\hline $\mathrm{BMI}, \mathrm{kg} / \mathrm{m}^{2}$ & $22.79 \pm 2.09$ & $21.32 \pm 2.16$ & 0.071 & $22.68 \pm 2.37$ & $22.72 \pm 3.12$ & 0.258 \\
\hline Smoking, n (\%) & $4(14.8 \%)$ & $7(53.8 \%)$ & 0.015 & $2(10.5 \%)$ & $9(42.9 \%)$ & 0.025 \\
\hline Drinking, n (\%) & $4(14.8 \%)$ & $4(30.8 \%)$ & 0.221 & $3(15.8 \%)$ & $5(23.8 \%)$ & 0.408 \\
\hline Hypertension, n (\%) & $20(74.1 \%)$ & $9(69.2 \%)$ & 0.514 & $14(73.7 \%)$ & $15(71.4 \%)$ & 0.578 \\
\hline Diabetes, n (\%) & 7 (25.9\%) & $3(23.1 \%)$ & 0.586 & $5(26.3 \%)$ & $5(23.8 \%)$ & 0.571 \\
\hline Dyslipidemia, n (\%) & 15 (55.6\%) & $7(53.8 \%)$ & 0.711 & $10(52.6 \%)$ & $12(57.1 \%)$ & 0.530 \\
\hline$W B C, \times 10^{9} / L$ & $7.74 \pm 3.78$ & $10.16 \pm 5.24$ & 0.104 & $7.89 \pm 3.75$ & $9.11 \pm 4.92$ & 0.417 \\
\hline Hemoglobin, g/dl & $129.70 \pm 24.17$ & $119.00 \pm 30.95$ & 0.239 & $130.47 \pm 21.25$ & $122.38 \pm 30.75$ & 0.312 \\
\hline Platelets, $\times 10^{9} / \mathrm{L}$ & $216.59 \pm 82.05$ & $251.08 \pm 103.42$ & 0.260 & $207.63 \pm 76.35$ & $246.05 \pm 98.52$ & 0.396 \\
\hline Serum creatinine, $\mu \mathrm{mol} / \mathrm{L}$ & $79.56 \pm 32.38$ & $70.62 \pm 39.07$ & 0.449 & $77.63 \pm 36.51$ & $75.76 \pm 33.36$ & 0.941 \\
\hline $\mathrm{CRP}, \mathrm{mg} / \mathrm{L}$ & $42.93 \pm 60.27$ & $82.57 \pm 96.68$ & 0.138 & $38.52 \pm 56.93$ & $73.99 \pm 88.82$ & 0.132 \\
\hline D-dimer, ug/mL & $3.91 \pm 4.93$ & $5.85 \pm 6.30$ & 0.292 & $3.546 \pm 4.36$ & $5.44 \pm 6.17$ & 0.245 \\
\hline Hcy, umol/L & $14.21 \pm 5.45$ & $14.69 \pm 11.00$ & 0.878 & $15.02 \pm 5.39$ & $13.79 \pm 9.04$ & 0.672 \\
\hline Cys-C, mg/L & $1.05 \pm 0.50$ & $0.93 \pm 0.31$ & 0.471 & $1.05 \pm 0.58$ & $0.97 \pm 0.28$ & 0.599 \\
\hline Family history of AAA, $n(\%)$ & $2(7.4 \%)$ & $1(7.7 \%)$ & 0.704 & $1(5.3 \%)$ & $2(9.5 \%)$ & 0.538 \\
\hline Max. aortic diameter, cm & $5.97 \pm 2.10$ & $6.32 \pm 2.05$ & 0.667 & $6.37 \pm 2.34$ & $5.79 \pm 1.75$ & 0.436 \\
\hline$>5.5$ cm, n (\%) & $8(29.6 \%)$ & $9(69.2 \%)$ & 0.022 & $8(42.1 \%)$ & $9(42.9 \%)$ & 0.500 \\
\hline$\leq 5.5 \mathrm{~cm}, \mathrm{n}(\%)$ & $16(59.3 \%)$ & $3(23.1 \%)$ & & $10(52.6 \%)$ & $9(42.9 \%)$ & \\
\hline Missing, n (\%) & $3(11.1 \%)$ & $1(7.7 \%)$ & & $1(5.3 \%)$ & $3(14.3 \%)$ & \\
\hline Max. aortic area, $\mathrm{cm}^{2}$ & $22.38 \pm 14.60$ & $27.71 \pm 15.84$ & 0.389 & $25.89 \pm 17.61$ & $23.52 \pm 13.68$ & 0.801 \\
\hline \multicolumn{7}{|l|}{ Thrombus within AAA } \\
\hline Yes, n (\%) & $10(37.0 \%)$ & $7(53.8 \%)$ & 0.200 & $5(26.3 \%)$ & $12(57.1 \%)$ & 0.013 \\
\hline No, n (\%) & $14(51.9 \%)$ & $4(30.8 \%)$ & & $13(68.4 \%)$ & $5(23.8 \%)$ & \\
\hline Missing, n (\%) & $3(11.1 \%)$ & $2(15.4 \%)$ & & $1(5.3 \%)$ & $4(19.0 \%)$ & \\
\hline
\end{tabular}

Table 4 Relationship of TLR4 and MMP9 expression level in situ with common circulating biomarkers and maximal AAA size

\begin{tabular}{|c|c|c|c|c|}
\hline \multirow[t]{2}{*}{ Correlated parameters } & \multicolumn{2}{|c|}{ TLR4 level } & \multicolumn{2}{|c|}{ MMP9 level } \\
\hline & $r$ & $P$ value & $r$ & $P$ value \\
\hline CRP, mg/L & 0.419 & 0.011 & 0.352 & 0.035 \\
\hline D-dimer, ug/mL & 0.204 & 0.208 & 0.183 & 0.257 \\
\hline Hcy, umol/L & 0.144 & 0.463 & 0.368 & 0.054 \\
\hline Cys-c, mg/L & 0.095 & 0.577 & 0.002 & 0.990 \\
\hline Max. aortic diameter, cm & 0.107 & 0.560 & 0.033 & 0.857 \\
\hline Max. aortic area, $\mathrm{cm}^{2}$ & 0.120 & 0.560 & 0.151 & 0.462 \\
\hline TLR4 level & - & - & 0.767 & $<0.001$ \\
\hline MMP9 level & 0.767 & $<0.001$ & - & - \\
\hline
\end{tabular}

for MMP9 having an elevated ratio of high expression in lymphocytes in comparison with TLR4 expression, there was an almost consistent pattern of TLR4 and MMP9 staining in overall cells, macrophages and SMCs.

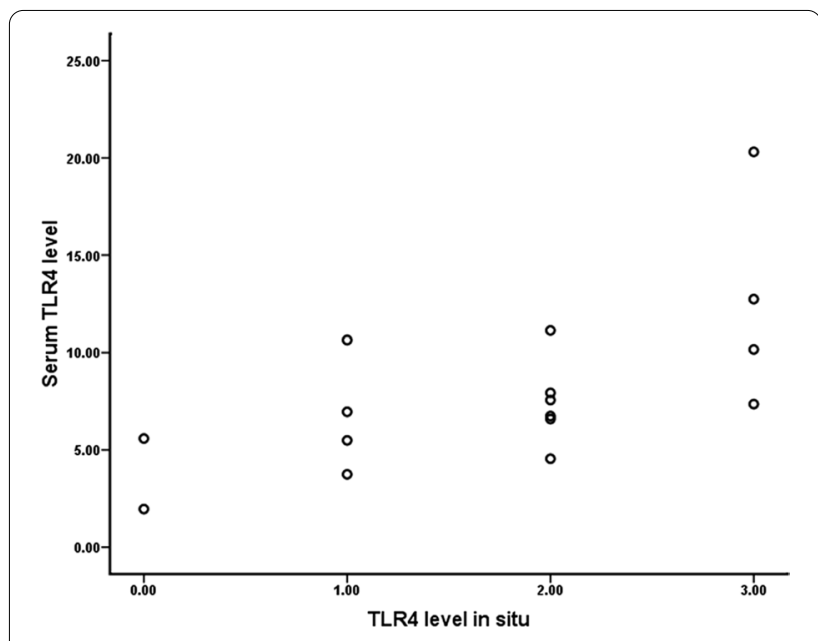

Fig. 5 Correlation between aortic TLR4 expression and serum TLR4 level in AAA patients 
Table 5 Multivariate logistic regression analysis of TLR4 and MMP9 expression in situ with AAA size and thrombus

\begin{tabular}{|c|c|c|c|c|}
\hline \multirow[t]{2}{*}{ Variables } & \multicolumn{2}{|c|}{ AAA size $(>5.5 \mathrm{~cm}$ vs. $\leq 5.5 \mathrm{~cm})$} & \multicolumn{2}{|c|}{ Thrombus within AAA (yes vs. no) } \\
\hline & OR $(95 \% \mathrm{Cl})$ & $P$ value ${ }^{a}$ & OR $(95 \% \mathrm{Cl})$ & $P$ value \\
\hline TLR4 expression (high vs. low) & $6.211(1.226-31.480)$ & 0.027 & $2.006(0.427-9.426)$ & 0.378 \\
\hline MMP9 expression (high vs. low) & $1.275(0.325-5.004)$ & 0.728 & $5.494(1.181-25.562)$ & 0.030 \\
\hline
\end{tabular}

a $P$ value after the adjustment for hypertension

${ }^{\mathrm{b}} P$ value after the adjustment for smoking and hypertension

Based on different TLR4 and MMP9 expression, we compared clinical characteristics of AAA patients. The results indicated that high TLR4 expression was more frequent in smoking patients and large AAA compared with low TLR4 expression. Smoking can promote the production of TLR4 and inflammatory cytokines involving in immunologic dysfunction [35, 36]. Regarding surrogate markers of AAA growth, aortic diameter is still the most widely used indicator of AAA progress [37]. Although we did not observe a statistical correlation of TLR4 level with aortic diameter or area in AAA wall, multiple analysis showed that high TLR4 expression could result in a 6.211-fold higher risk of large AAA formation compared with low TLR4 expression. Above data suggested that TLR4 in AAA wall could be involved in the immune-inflammatory response associated with larger aortic size. In previous studies, MMP9 expression was reported elevated in AAA with a diameter $\geq 5.5 \mathrm{~cm}$ and its activity varied with aortic diameter in AAA, but the results were inconclusive $[16,17,28]$. However, our findings failed to suggest an association between MMP9 expression and AAA size. Interestingly, we found that high MMP9 expression in situ had a significantly higher ratio of thrombus within AAA than low MMP9 expression. Even after adjusting the potential confounders, the relationship between high MMP9 expression and occurrence of thrombus within AAA lesions remained significant. This finding may be explained by the fact that high MMP9 levels associated with increased protease activity can be implicated in complement-coagulation crosstalk in aneurysm wall, leading to the formation of thrombus [38]. In turn, intraluminal thrombus may disrupt the underlying AAA wall integrity and promote aortic wall degradation by enhancing MMP9 secretion [39, 40].

Being a sensitive inflammatory biomarker, CRP was widely used in daily clinical practice for monitoring the initiation and progression of AAA [41, 42]. It has been reported that CRP can induce TLR4 and MMP9 production in inflammatory and vascular cells [43, 44], while TLR4 may enhance the effect of CRP in the vessel [45]. Above evidence could partly explain our results that either TLR4 or MMP9 expression level was positively associated with the concentration of circulating CRP in
AAA patients. Furthermore, experiments have demonstrated the role of TLR4 pathway on inducing MMP9 production from inflammatory cells and SMCs [19, 21], in turn, components from aortic wall degradation are known triggers for TLR4 and its signaling activation [9]. Interestingly, our data for the first time determined an association between TLR4 and MMP9 expression in human AAA tissues, which contributed to a better understanding of a cross-talk between inflammation and ECM degradation related genes observed in the mechanism of AAA. In addition, our research identified a significant positive correlation of TLR4 expression in situ with its serum level, suggesting that highly upregulated TLR4 expression in AAA tissues brought about the elevated TLR4 expression in serum, which would be valuable from a clinical perspective.

There were several limitations in our study. First, the present research was an observational analysis on surgical AAA specimens and could not reflect the earlier stages of aneurysm formation. Second, the sample size of AAA tissues was relatively small due to the prevalence of endovascular aneurysm repair over open surgical repair. Third, it was extremely difficult to obtain healthy aortic samples, and no clinical information was available for controls. In addition, we could not evaluate the effects of TLR4 and MMP9 expression on AAA progression because of no data concerning rate of AAA growth. Therefore, future studies with larger sample size and collection of AAA growth rate for analysis are warranted.

\section{Conclusions}

This study focused on the expression characteristics of TLR4 and MMP9 in human AAA tissues by means of immunohistochemistry. The results demonstrated that both TLR4 and MMP9 were abundantly expressed in AAA tissue samples, particularly localized to lymphocytes and SMCs. Furthermore, our findings shed light on a good correlation between TLR4 and MMP9 expression within human AAA wall. And TLR4 expression in situ was positively associated with its serum level. In addition, multiple analyses indicated that TLR4 expression independently influenced the size of AAA, while MMP9 level affected the incidence of thrombus within AAA. Thus, the expression 
and appearance of TLR4 and MMP9 may serve as a potential target to detect aortic wall damage degree in AAA patients. Further functional studies are necessary to elucidate the combined role of TLR4 and MMP9 in AAA development and to address its possible interest as a prognostic or therapeutic target in aneurysmal disease.

\begin{abstract}
Abbreviations
AAA: Abdominal aortic aneurysm; ECM: Extracellular matrix; TLR4: Toll-like receptor 4; SMCs: Smooth muscle cells; MMP9: Matrix metalloproteinase 9; CTA: Computed tomography angiography; DAB: Diaminobenzidine; CRP: C-reactive protein
\end{abstract}

\section{Acknowledgements}

The authors would like to particularly thank Yuan Yuan and Jingjing Jing for their excellent technical support in the immunohistochemical staining and scores.

\section{Authors' contributions}

$T L$ performed the experiments, analyzed the data and wrote the manuscript. $X L 1$ and XL2 collected the tissue samples and clinical data. JY participated in the study design. CM revised the work critically for important intellectual content. All authors have read and approved the final manuscript.

\section{Funding}

This study was supported by grants from the National Natural Science Foundation of China (82001828 and 81871373), Natural Science Foundation of Liaoning Province (2020-BS-102) and Backbone Youth Support Project (Natural Science) of China Medical University (QGZ2018007). The funding bodies played no role in the design of the study and collection, analysis, and interpretation of data and in writing the manuscript.

\section{Availability of data and materials}

The datasets generated and/or analyzed during the current study are available from the corresponding author on reasonable request.

\section{Declarations}

\section{Ethics approval and consent to participate}

The study was approved by the Ethics Committee of the First Hospital of China Medical University (Shenyang, China) and was according to the Declaration of Helsinki. Written informed consent was obtained from each subject.

\section{Consent to publish}

Not applicable.

\section{Competing interests}

The authors declare that they have no competing interests.

\section{Author details \\ 'Department of Cardiovascular Ultrasound, the First Hospital of China Medical University, No. 155 Nanjing Bei Street, Heping District, Shenyang 110001, Liaoning Province, People's Republic of China. ${ }^{2}$ Department of Vascular and Thyroid Surgery, the First Hospital of China Medical University, Shen- yang 110001, People's Republic of China.}

Received: 23 September 2020 Accepted: 30 July 2021

Published online: 04 August 2021

\section{References}

1. Sakalihasan N, Limet R, Defawe OD. Abdominal aortic aneurysm. Lancet. 2005;365(9470):1577-89.

2. Toghill BJ, Saratzis A, Bown MJ. Abdominal aortic aneurysm-an independent disease to atherosclerosis? Cardiovasc Pathol. 2017;27:71-5.
3. Erbel R, Aboyans V, Boileau C, Bossone E, Bartolomeo RD, Eggebrecht $H$, Evangelista A, Falk V, Frank H, Gaemperli O, et al. ESC Guidelines on the diagnosis and treatment of aortic diseases: document covering acute and chronic aortic diseases of the thoracic and abdominal aorta of the adult. The Task Force for the Diagnosis and Treatment of Aortic Diseases of the European Society of Cardiology (ESC). Eur Heart J. 2014;35(41):2873-926.

4. Shang T, Ran F, Qiao Q, Liu Z, Liu CJ. Tanshinone IIA attenuates elastaseinduced AAA in rats via inhibition of MyD88-dependent TLR-4 signaling. Vasa. 2014;43(1):39-46.

5. Huggins C, Pearce S, Peri F, Neumann F, Cockerill G, Pirianov G. A novel small molecule TLR4 antagonist (IAXO-102) negatively regulates nonhematopoietic toll like receptor 4 signalling and inhibits aortic aneurysms development. Atherosclerosis. 2015;242(2):563-70.

6. Balistreri CR, Ruvolo G, Lio D, Madonna R. Toll-like receptor-4 signaling pathway in aorta aging and diseases: "its double nature." J Mol Cell Cardiol. 2017;110:38-53.

7. Takeda K, Kaisho T, Akira S. Toll-like receptors. Annu Rev Immunol. 2003;21:335-76.

8. Pisano C, Balistreri CR, Ricasoli A, Ruvolo G. Cardiovascular disease in ageing: an overview on thoracic aortic aneurysm as an emerging inflammatory disease. Mediators Inflamm. 2017;2017:1274034.

9. Vorkapic E, Lundberg AM, Mayranpaa MI, Eriksson P, Wagsater D. TRIF adaptor signaling is important in abdominal aortic aneurysm formation. Atherosclerosis. 2015;241(2):561-8.

10. Lai CH, Wang KC, Lee FT, Tsai HW, Ma CY, Cheng TL, Chang BI, Yang YJ, Shi GY, Wu HL. Toll-like receptor 4 is essential in the development of abdominal aortic aneurysm. PLOS ONE. 2016;11(1):e0146565.

11. Guo DC, Papke CL, He R, Milewicz DM. Pathogenesis of thoracic and abdominal aortic aneurysms. Ann NY Acad Sci. 2006;1085:339-52.

12. Howatt DA, Dajee M, Xie X, Moorleghen J, Rateri DL, Balakrishnan A, Da Cunha V, Johns DG, Gutstein DE, Daugherty A, et al. Relaxin and matrix metalloproteinase-9 in angiotensin II-induced abdominal aortic aneurysms. Circ J. 2017;81(6):888-90.

13. Vasic N, Glumac S, Pejic S, Amidzic L, Tadic Latinovic LJ, Dozic B, Hinic S, Maksimovic Z. Expression of matrix metalloproteinases and endogenous inhibitors in abdominal aortic aneurysm and aortoiliac occlusive disease (Syndrome Leriche). Folia Biol (Praha). 2017;63(5-6):209-16.

14. Kowalewski R, Sobolewski K, Malkowski A, Wolanska M, Gacko M. Evaluation of enzymes involved in proteoglycan degradation in the wall of abdominal aortic aneurysms. J Vasc Res. 2006:43(1):95-100.

15. Rabkin SW. The role matrix metalloproteinases in the production of aortic aneurysm. Prog Mol Biol Transl Sci. 2017;147:239-65.

16. Freestone T, Turner RJ, Coady A, Higman DJ, Greenhalgh RM, Powell JT. Inflammation and matrix metalloproteinases in the enlarging abdominal aortic aneurysm. Arterioscler Thromb Vasc Biol. 1995;15(8):1145-51.

17. McMillan WD, Tamarina NA, Cipollone M, Johnson DA, Parker MA, Pearce WH. Size matters: the relationship between MMP-9 expression and aortic diameter. Circulation. 1997;96(7):2228-32.

18. Groeneveld ME, van Burink MV, Begieneman MP, Niessen HW, Wisselink W, Eringa EC, Yeung KK. Activation of extracellular signal-related kinase in abdominal aortic aneurysm. Eur J Clin Invest. 2016;46(5):440-7.

19. Li H, Xu H, Liu S. Toll-like receptors 4 induces expression of matrix metalloproteinase-9 in human aortic smooth muscle cells. Mol Biol Rep. 2011;38(2):1419-23.

20. Li H, Xu H, Sun B. Lipopolysaccharide regulates MMP-9 expression through TLR4/NF-kappaB signaling in human arterial smooth muscle cells. Mol Med Rep. 2012;6(4):774-8.

21. Qin Z, Bagley J, Sukhova G, Baur WE, Park HJ, Beasley D, Libby P, Zhang Y, Galper JB. Angiotensin II-induced TLR4 mediated abdominal aortic aneurysm in apolipoprotein E knockout mice is dependent on STAT3. J Mol Cell Cardiol. 2015;87:160-70.

22. Qiu J, Xu J, Zheng Y, Wei Y, Zhu X, Lo EH, Moskowitz MA, Sims JR. High-mobility group box 1 promotes metalloproteinase-9 upregulation through toll-like receptor 4 after cerebral ischemia. Stroke. 2010:41(9):2077-82.

23. Teo FH, de Oliveira RTD, Villarejos L, Mamoni RL, Altemani A, Menezes $\mathrm{FH}$, Blotta M. Characterization of CD4(+) T cell subsets in patients with abdominal aortic aneurysms. Mediators Inflamm. 2018;2018:6967310.

24. LiT, Jiang B, Li X, Sun HY, Li XT, Jing JJ, Yang J. Serum matrix metalloproteinase- 9 is a valuable biomarker for identification of abdominal and 
thoracic aortic aneurysm: a case-control study. BMC Cardiovasc Disord. 2018;18(1):202.

25. Li T, Jing JJ, Sun LP, Gong YH, Dong NN, Yang J, Yuan Y. Serum Toll-like receptor 4: a novel and promising biomarker for identification of aortic aneurysmal diseases. Clin Chim Acta. 2018;483:69-75.

26. Jing JJ, Lu YZ, Sun LP, Liu JW, Gong YH, Xu Q, Dong NN, Yuan Y. Epistatic SNP interaction of ERCC6 with ERCC8 and their joint protein expression contribute to gastric cancer/atrophic gastritis risk. Oncotarget. 2017:8(26):43140-52.

27. Qu Z, Cheuk BL, Cheng SW. Differential expression of sphingosine1-phosphate receptors in abdominal aortic aneurysms. Mediators Inflamm. 2012;2012:643609.

28. Dilme JF, Bellmunt S, Camacho M, Sola-Villa D, Romero JM, Escudero JR, Vila L. Influence of cardiovascular risk factors on levels of matrix metalloproteinases 2 and 9 in human abdominal aortic aneurysms. Eur J Vasc Endovasc Surg. 2014;48(4):374-81.

29. Tanios F, Pelisek J, Lutz B, Reutersberg B, Matevossian E, Schwamborn K, Hosel V, Eckstein HH, Reeps C. CXCR4: a potential marker for inflammatory activity in abdominal aortic aneurysm wall. Eur J Vasc Endovasc Surg. 2015:50(6):745-53.

30. Raffort J, Lareyre F, Clement M, Hassen-Khodja R, Chinetti G, Mallat Z. Monocytes and macrophages in abdominal aortic aneurysm. Nat Rev Cardiol. 2017;14(8):457-71.

31. Jablonska A, Neumayer C, Bolliger M, Burghuber C, Klinger M, Demyanets $\mathrm{S}$, Nanobachvili J, Huk I. Insight into the expression of toll-like receptors 2 and 4 in patients with abdominal aortic aneurysm. Mol Biol Rep. 2020:47(4):2685-92.

32. Xiong F, Zhao JC. Quantification and location of Chlamydia pneumoniaespecific antigen in the walls of abdominal aortic aneurysms. Ann Vasc Surg. 2011;25(2):256-63.

33. Shin S, Cho YP, Jun H, Park H, Hong HN, Kwon TW. Transglutaminase type 2 in human abdominal aortic aneurysm is a potential factor in the stabilization of extracellular matrix. J Vasc Surg. 2013;57(5):1362-70.

34. Monux G, Zamorano-Leon JJ, Marques P, Sopena B, Garcia-Garcia JM, Laich de Koller G, Calvo-Rico B, Garcia-Fernandez MA, Serrano J, LopezFarre A. FXa inhibition by rivaroxaban modifies mechanisms associated with the pathogenesis of human abdominal aortic aneurysms. Br J Clin Pharmacol. 2017:83(12):2661-70.

35. Semlali A, Witoled C, Alanazi M, Rouabhia M. Whole cigarette smoke increased the expression of TLRs, HBDs, and proinflammory cytokines by human gingival epithelial cells through different signaling pathways. PLOS ONE. 2012;7(12):e52614.
36. Gaydos J, McNally A, Guo R, Vandivier RW, Simonian PL, Burnham EL. Alcohol abuse and smoking alter inflammatory mediator production by pulmonary and systemic immune cells. Am J Physiol Lung Cell Mol Physiol. 2016;310(6):L507-18.

37. Wanhainen A, Mani K, Golledge J. Surrogate markers of abdominal aortic aneurysm progression. Arterioscler Thromb Vasc Biol. 2016;36(2):236-44.

38. Piechota-Polanczyk A, Demyanets S, Mittlboeck M, Hofmann M, Domenig CM, Neumayer C, Wojta J, Klinger M, Nanobachvili J, Huk I. The influence of simvastatin on NGAL, matrix metalloproteinases and their tissue inhibitors in human intraluminal thrombus and abdominal aortic aneurysm tissue. Eur J Vasc Endovasc Surg. 2015;49(5):549-55.

39. Koole D, Zandvoort HJ, Schoneveld A, Vink A, Vos JA, van den Hoogen $L L$, de Vries JP, Pasterkamp G, Moll FL, van Herwaarden JA. Intraluminal abdominal aortic aneurysm thrombus is associated with disruption of wall integrity. J Vasc Surg. 2013;57(1):77-83.

40. Coutard M, Touat Z, Houard X, Leclerca A, Michel JB. Thrombus versus wall biological activities in experimental aortic aneurysms. J Vasc Res. 2010:47(4):355-66

41. Golledge J, Tsao PS, Dalman RL, Norman PE. Circulating markers of abdominal aortic aneurysm presence and progression. Circulation. 2008;118(23):2382-92.

42. Hellenthal FA, Buurman WA, Wodzig WK, Schurink GW. Biomarkers of abdominal aortic aneurysm progression. Part 2: inflammation. Nat Rev Cardiol. 2009;6(8):543-52.

43. Nabata A, Kuroki M, Ueba H, Hashimoto S, Umemoto T, Wada H, Yasu T, Saito M, Momomura S, Kawakami M. C-reactive protein induces endothelial cell apoptosis and matrix metalloproteinase-9 production in human mononuclear cells: implications for the destabilization of atherosclerotic plaque. Atherosclerosis. 2008;196(1):129-35.

44. Liu N, Liu JT, Ji YY, Lu PP. C-reactive protein triggers inflammatory responses partly via TLR4/IRF3/NF-kappaB signaling pathway in rat vascular smooth muscle cells. Life Sci. 2010;87(11-12):367-74.

45. Haider DG, Leuchten N, Schaller G, Gouya G, Kolodjaschna J, Schmetterer L, Kapiotis S, Wolzt M. C-reactive protein is expressed and secreted by peripheral blood mononuclear cells. Clin Exp Immunol. 2006;146(3):533-9.

\section{Publisher's Note}

Springer Nature remains neutral with regard to jurisdictional claims in published maps and institutional affiliations.
Ready to submit your research? Choose BMC and benefit from:

- fast, convenient online submission

- thorough peer review by experienced researchers in your field

- rapid publication on acceptance

- support for research data, including large and complex data types

- gold Open Access which fosters wider collaboration and increased citations

- maximum visibility for your research: over $100 \mathrm{M}$ website views per year

At BMC, research is always in progress.

Learn more biomedcentral.com/submissions 